\title{
Challenges and Factors affecting the implementation of e-Government in Iraq
}

\author{
Nooruldeen Nasih Qader \\ College of Science and Technology \\ University of Human Development \\ nooruldeen.qader@uhd.edu.iq
}

\author{
Mohammed Qader Kheder \\ School of Science and Educational Sciences \\ University of Sulaimani \\ mohammed.kheder@univsul.edu.iq
}

\begin{abstract}
Government refers to the use of Information Technology by the government agencies, namely, the Internet, Mobile Computing and Wide Area Network which have the ability to transfer relations with businesses, citizens, other governments and the other arms of the government. Therefore, the main facilities of the eGovernment is to provision of relevant government information in electronic form to the citizens in a timely manner, empowerment of the people through access to information without the administration, make the best delivery to citizens, enhanced productivity and reduce cost or saving cost in doing business with suppliers and customers of government and contribution in public policy decision making. The primary objective of this paper is to review the available and up to date literature about eGovernment implementation stages, its benefits and challenges. Depending on literature, the paper reviews a number of relevant issues regarding Iraqi e-Government, namely, e-Government definition, implementation stages, 'ereadiness', the benefits of e-Government implementation and it focuses on the challenges of Iraqi e-Government implementation.
\end{abstract}

Keywords- E-Government, Iraqi e-Government, EGovernance, E-Services, Challenges, Factors.

\section{INTRODUCTION}

E-Government is a new area of study in the field of the Information System (IS) which is related to the use of Information and Communication Technology (ICT) by the government organizations to electronically deliver its services [14]. Furthermore, e-Government refers to the use of Information Technology (IT) by the government agencies such as, the Internet, Wide Area Networks and Mobile Computing that have the ability to transfer relations with businesses, other governments, citizens and the other arms of the government. The technologies which have mentioned previous will be able to serve a variety of different ends, namely, citizens' empowerment via access information, enhanced delivery of government services to citizens, more competent the government management, or better interactions with businesses and industries. The benefits of the result could be less corruption, superior convenience, improved transparency, cost reductions and revenue development. Using a new technology like a computer in life being important, citizens have become more the 'Internet savvy' and experience good e-services from the private sector, they have initiated to expect the same high standards from the government agencies [2].

E-Government has become a popular focus of government attempts in los of countries around the world. There are many governments in the world have implemented e-Government projects as a means of improving services, reducing costs, rising effectiveness, saving time and efficiency in the public sector [1][2]. The Internet and e-Government has made a vital change in the whole society structure, culture, values, and the ways of conducting business by using the possible of ICT as a tool in the daily work. The main objective of eGovernment is not just the conversion of traditional information into 'Bits and Bytes' and making it reachable through the Internet, or giving government official computers or automating old practices to an electronic platform. Other than, it calls for rethinking ways the government purposes are accomplished today in order to get better integration and processes [1].

It has become obvious, particularly in the last decades that there is a global shift towards e-Government with the purpose to introduce radical changes to the traditional approach of public services delivery. Furthermore, e-Governments are argued to be very important in developing the public sectors around the globe, as it promises more and more transparency and accountability [4]. There are lots of countries which have been confronting complexities, for instance decision making processes are centralized, organization in systems, redundancy leading to difficulties in the public sector, the absence of strong ICT infrastructure and coordination and poor sharing of information. Due to the fact that the concepts of e-Government are emerging, governments around the world also have known the significance of giving their services efficiently. It is really clear that citizens have been becoming skillful with the Internet technologies and getting pleasure from better electronic services from private sectors, and they also expect the same from the government sectors [4][5]. EGovernment attempts to match the private sectors by delivering transparent and efficient services to businesses in addition to citizens, in spite the fact that positive outputs of the e-Government services are obtainable in documents, the rolling out as well as implementation 
these concepts are in low level in developing and developed countries in the around the world [5].

Because of the current situation of security since 2003, the government of Iraq discovers itself coming to terms with how the progress to be in way of development. In June 2004, the United States calls on Member Nations to aid the new government of Iraq for institution building. Furthermore, Italian minister for Technologies and Innovations and the Iraqi minister of Science and Technology sign a memorandum of understanding in which the government of Italian commits to offer technical and financial support for the construction of an Intranet linking the ministries of the new Iraqi government and built an e-Government project. It can be said that the Intranet project represents the initial step for the development of an efficient eGovernment platform.

\section{LITERATURE REVIEW}

The critically of having recognition system in place is spoken by having the proposal appearing at rank number two in the top ten lists of critical e-Government projects. Therefore, in the delivery of services to its citizens, a government has to have in place a system that enables identification of citizens which in turn assists establishes the characteristics of citizens who qualify for a certain services. This paper focuses on the challenges and barriers faced in the achievement of the identification system in the government of Iraq. So, the challenges and barriers are known based on the aspects of political, ICT skill, technology types, electricity and connectivity [3]. Increase the availability of essential hardware and software for e-Government services, namely, the Internet access and support and user guidance particularly in place where less advantaged citizens are discovered [4]. The suggested conceptual framework has been empirically tested using a recently developed structured questionnaire. The data were gathered from a sample of five hundred forty seven Greek citizens. The results show that the perceived usefulness is the most vital determinant of the meaning to use e-Government services [6]. According to [4], which discovered the approach towards e-Government of a sample of 220 graduated students at various universities in Lebanon, using a survey with 'cognitive', affective and 'conative' dimensions. It can be say the cognitive dimension refers to awareness, the purpose of using e-Government and the affective dimension to peoples' emotions towards e-Government. The result of this survey illustrated a direct relationship between the cognitive and conative dimensions, whereas the dimension of affective feelings has been found to be less important [4].

Heeks in 2003, argued that the main problem behind e-Government project breakdown in developing countries is caused by the gap between the reality and design in terms of information, processes objectives and values, technology, management systems, staffing and skills and the other resources for instance, time and money [7]. There are many finding of studies which showed that the culture had little effect on the implementation of e-Government. On the other hand, they demonstrated that a lack of trust and confidence by clients and a lack of good laws and legislation had a large effect on the adoption of e-Government. [17] considered the factors affecting e-Government implementation in the state of Qatar. They obtained effort expectance and social influence to manipulate the intention to use eGovernment services, and also use purpose to influence real use of the services. Furthermore, ALAwadhi and Morris who are in Kuwait applied a customized UTAUT model to e-Government services implementation [18]. They could find the performance expectancy and attempt expectancy to influence use intention, in addition to facilitating conditions and utilize intention to manipulate actual use of the service. They also found the Internet knowledge improved the effect of performance expectancy on use intention in the short run. What's more, [19] made bigger TAM model to examine the factors which support citizens who are in the United Arab Emirates (UAE) to accept e-Government. The outcomes encouraged their model in predicating citizens' attitudes towards e-Government agenda. As the study was conducted within Qualitative research, in which authors in this paper should find the challenges against the development process in the Iraqi e-Government project, the authors needed to gather data that is connected to Iraqi e-Government project. Due to the fact that the choice of face-to-face interview is very essential to select the right person who provide the authors the best data that will be excellent data for research [2].

There are lots of researches which have been done to identify the citizens' adoption factors of e-Government for developed countries, though for developing countries such studies are less and for the government of Iraq (where the citizens' implementation of e-Government services is extremely low), there is none and this study is aimed at addressing this big gap. This study wants to mention the e-Government of Sri Lanka, since it is so closest from the Iraqi e-Government and it can be obtained some good points from Sri Lanka e-Government for instance, how citizens can use government services. Sri Lanka government applied the project of eGovernment in 2002. The launching of Sri Lanka Gate, the official portal "www.lk.or.srilanka.lk" of Sri Lanka, on the Internet was the implementation step of the eGovernment (e-Srilanka) project by the government [5]. According to Sri Lanka Gate (2013), by using the eSrilanka site, citizens are enabled to get more than twenty electronic services, namely, issuance of examination certificates, e-revenue license issuance, updates information from the Sri Lanka government agencies and the other e-services such as, payment for the government services like electricity [5]. According to e-Government ranking in the world in 2012, out of the top twenty eGovernment leaders, three of them are from Asia such as, Japan, Republic of Korea and Singapore. It can make the regionally compared that the Asia as a whole has a higher level of e-Government than the rest of the world. 
Furthermore, Sri Lanka secured $115^{\text {th }}$ place in this ranking, however it was in $111^{\text {th }}$ place in 2010 (UN eGovernment survey 2012), while Sri Lanka carries out better than several other big countries in the region [5]. Based on those finding that have mentioned before, it can obtain lots of benefits from them to implement the Iraqi e-Government. Furthermore, the challenges of Iraqi eGovernment could be worked out by do not coming back on the challenges that have discovered in the above researches' challenges.

\section{E-GOVERNMENT DEFINITION}

The explosive entry of technology into each aspect of life has changed how people manage their works, how they live, how companies and organizations do business and how governments serve their people. Therefore, it can be defined e-Government is the use of technology to improve the access to a delivery of government services to benefit citizens, employees and business partners. EGovernment is a common term for Web-Based services from a general of federal and state government. In the term of E-Government, the government uses IT and particularly the Internet to hold up government operations, engage citizens and offer government services [3]. According to [2][15], the e-Government as the use of IT in particular sector to reach out to its inhabitants in a modern and effective way. Moreover, in simplest term, eGovernment could be defined as the provision of government information via the Internet to citizens and business among government agencies.

There are four primary blocks of e-Government:

- G2C (Government to Citizens): allow citizens to retrieve information and complete government transactions, such as license renewals.

- G2G (Government to Government) online interaction and communication among government agencies.

- G2B (Government to Business) allows businesses to get back government information and complete transactions with government agencies, for instance bid submission.

- G2E (Government to Employee) employees can use online to interact with the government.

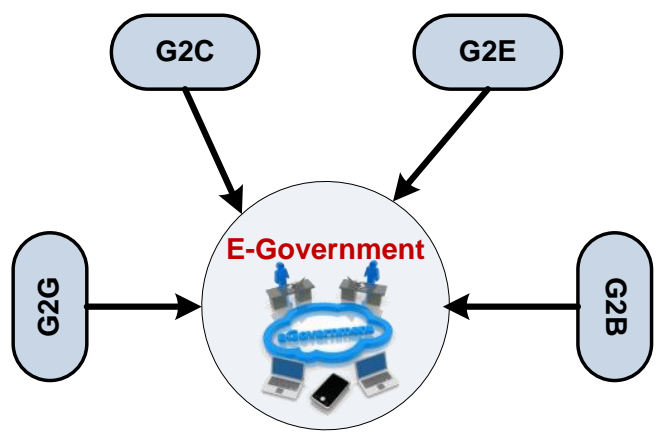

Figure 1: e-Government Types
E-Governance uses information and communication technology (ICT) at different levels of the government and the public sector, for the reason of improving governance Furthermore, e-Government in simplified words is the usage of ICT to conduct information distribution and to do various types of transaction with inhabitants, business and the other government agencies, is one of the outcomes of rapidly rising technology development [15]. In the last few years, there has been much talk about m-Government which stands for Mobile Government. M-Government refers to the use of wireless technology, namely, mobile phone or cellular, laptops and personal digital assistance (PDA) for providing and delivering government services. It cannot be said that the m-Government is a substitute for eGovernment, rather it complements it.

\section{IRAQ STAGES OF E-GOVERNMENT}

The Iraqi Government is in the unique position of developing an e-Government strategy in an environment which is receptive to innovative idea. These communications and information ideas might be catalysts of a positive future. Enduring leadership is necessary from a respected group from within the Iraqi government structure to drive new plan. Because of the present state of security since 2003, the government of Iraq finds itself coming to terms with how to progress like a nation. The main target of the government strategy has to address issues on economic, social and political fronts [9]. The Iraqi government, since 2003 has suffered political incompatibility and unsteadiness. Such situation is reproduced in its performance of the government in offering services at all government agencies [3]. Certainly, it can be said that the technology of the Internet is the most pervasive advancement which could be leveraged by almost every organization. The government of Iraq and its citizens are no exceptions. Founded on the UN e-Government services index; the Iraq ranks at number 134 states in 2014. This rank can be attributed to the instability of the country following the 2003 attack of Iraq. Taken the situation resulting from the war, lots of the Iraq development plans have come to stop the progress of. Although, they require to establishment an effective and efficient e-Government for Iraq is high on the country's agenda, the challenges and situations that might hold back the progress have to first be systematically understood identification system [3][9].

\section{IRAQI E-GOVERNMENT CHALLENGES}

It is really normal when we are going to talk about the challenges of applying e-Government due to the fact that all the government when they attempt to apply the various types of technologies to manage their works they have lots of problems in the beginning. However, they try to solve them during the progress. There are several 
challenges of Iraqi e-Government, such as culture (it is very hard to make people to believe in machine), policy issues (legislation), new forms of leadership, changing trends of new technology, ICT infrastructure, and the other challenges, but one of the biggest challenges to eGovernment development in Iraq at current has been the security situation [3][9]. Government becomes potential when staffs from government agencies have the chance to meet with each other, and discuss areas of project commonality. Offline and online relationships are paramount to the success of eventual electronic relationships. According to many Iraqi resources, in 2007 Iraq is still at the first stage of progress, as agencies begin to promote their services and highlights via a web presence. What's more, the higher level of human development, the more likely citizens will be inclined to accept and use e-Government services. Moreover, the support from high level is very important to eGovernment development, the gaining of needed resources and training, the coordination and cooperation between stakeholders and partners for a successful of eGovernment implementation. According to [9], the percentage of leaders and political decision makers who have knowledge in ICT in the government of Iraq is lower than $10 \%$. Also, it can be seen that the primary barriers to the implementation of e-Government are not technical, however cultural implementations of new technologies, as it presents in the below table.

\begin{tabular}{||l|l||}
\hline Category & Barriers \\
\hline \hline \multirow{4}{*}{ Technical } & ICT Infrastructure \\
\cline { 2 - 3 } & Privacy \\
\cline { 2 - 3 } Organizational & Security \\
\hline \hline \multirow{3}{*}{ Social } & Top management support \\
\cline { 2 - 3 } & Resistance to change to electronic ways \\
\cline { 2 - 3 } & Collaboration \\
\cline { 2 - 2 } & Lake of Qualified \\
\cline { 2 - 2 } & Personnel and Training \\
\hline \hline Financial & Digital Device \\
\cline { 2 - 2 } & Culture \\
\hline
\end{tabular}

Table 1: e-Government challenges category [1]

The government can interact with the governed by using e-Government since it transfers the way between them. However, the process is neither quick nor simple. The success of e-Government needs fundamentally changing of how the government works, and how people view the ways in which government assists them [12]. There are several factors which affect the use of eGovernment services, namely, security, trustworthiness, accessibility, digital device, mainstreaming, public awareness, level of education, legal framework, public acceptance, attitudes, cultural, political and the other factors such as, privacy issues [8][9]. Finally, it can be mentioned other challenges of Iraqi e-Government, for instance security, war against terrorism, ISIS and challenges during a variety of wars in Iraq.

\section{IRAQI E-GOVERNMENT AND INFORMATION TECHNOLOGY}

As it known e-Government is an essential area of IT and IS innovation, governments have been trying to incorporate e-Government into their existing IS applications and government processes [4]. The stage of electronic information distribution in the higher education sector of the government of Iraq is at its infancy that presents a challenge [11]. That is mostly true in the Western Asian region, where although huge sums of money have been spent and different ICT programs have been started on, the majority of Arab countries have faced several challenges which have slowed the implementation and adoption of their e-Government initiatives [4]. One of the main challenges for eGovernment is the ICT infrastructure, whilst developed counties have high IT literacy level compared to the developing countries [15]. Also, it can be said that the level of literacy of the citizens in those developing countries seems to be low compared to the industrialized countries with advanced technology. Furthermore, apart from bureaucracy, corruption and political barriers as a result of the government from $\mathrm{Cs} 2 \mathrm{Cs}$ (Countries to Countries) would determine the level of support and eGovernment applications need [15]. These barriers as detected in the developing countries involve economic constraints, socio cultural issues, infrastructural and technical constraints and change management problems resistance to change among public servants. What's more, there are other barriers which include in the developing countries such as, a lack of trust and confidence by users and a lack of proper legislation and laws [13].

\section{IRAQI E-GOVERNMENT IN GLOBAL RANKING INDEX}

The Republic of Iraq is located in the Western Asia, its capital is Baghdad where is the center of the country, and it is the large city. The total population of Iraq is about thirty six million. The official language of Iraq is Arabic and Kurdish, while English is also spoken. Iraq is a very lower income country governments are highly interested in the application of ICT to have a place in the global digital economy. As a result, the government of Iraq now is developing a strong ICT sector to be a competitive in this regard. Whenever using the UN e-Government readiness report, it ought to always be kept in mind that e-Government readiness index is a composite of three components: Telecommunication, Web Measure and Human Capital.

According to all the UN reports that have been published for the last decades, the Iraq government tried to improve the performance of e-Government. In 2010, Iraq's performance has improved significantly since the 2008 survey, as it took an amazing jump of 15 positions 
in the global ranking from being ranked $151^{\text {st }}$ in 2008 to $136^{\text {th }}$ in 2010 , this ranking indexed between 193 countries. The government of Iraq achieved a good development in e-Government services because the 2008 survey and being above the 2010 world average (0.2996). Furthermore, in terms of the e-Participation index, for instance Iraq had the best move upwards all over the world from being ranked $151^{\text {st }}$ in 2005 to $60^{\text {th }}$ in the 2008 survey [16]. However, this number was unbelievably rapidly increased to $101^{\text {st }}$ in 2012 and $152^{\text {nd }}$ in the 2014 survey because of economical issues. In 2014 Iraq has been ranked $134^{\text {th }}$ out of 193 of the Western Asia countries for the readiness index, with an overall index of 0.3141 out of 1.0, of which, 0.2173 for telecommunication infrastructure component, 0.1969 for online service component and 0.9619 for human capital component [16]. Below figure shows the UN ranking index in 2014 about Iraqi e-Government.

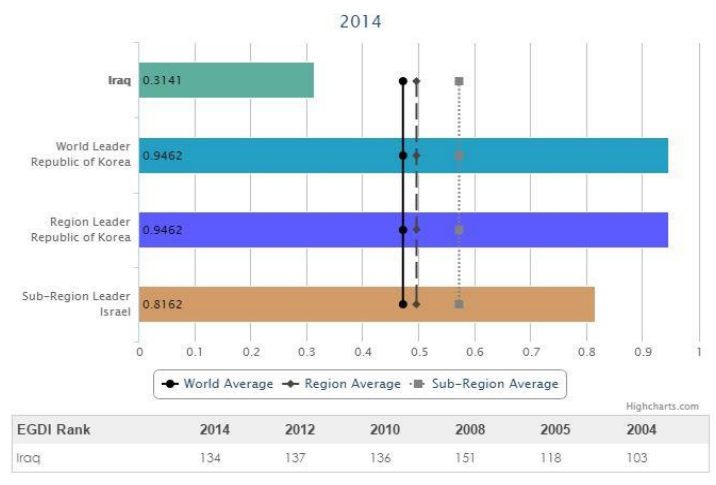

Figure 2: e-Government development index [16]

Figure 3 illustrates the e-Participation index of the government of Iraq in 2014.

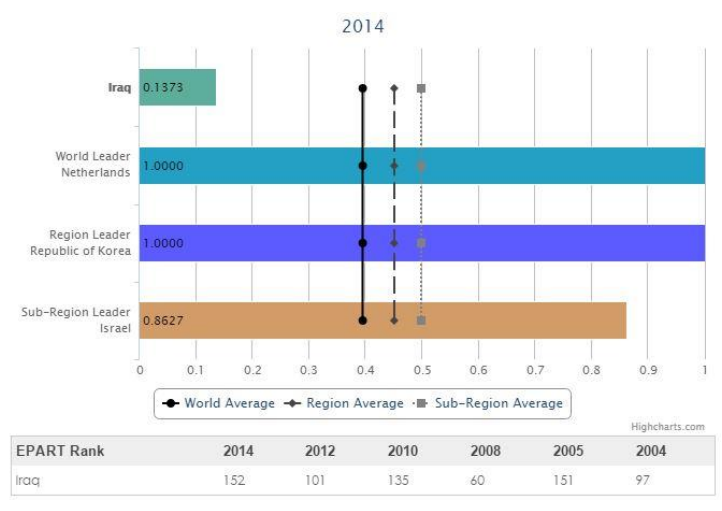

Figure 3: e-Participation index [16]

\section{DISCUSSION}

After freedom operation in Iraq by US in 2003, the government of Iraq began to build its own eGovernment project with the help of the government of Italy to have the place amongst world ICT society [9]. It can say this is Qualitative study, conducted in Ministry of Science and Technology in Iraq where the authors carry out several interviews with employees. The lack of faith, according to interviewees, is considered as one of the primary barriers to the implementation e-Government as well as services obtainable by the private mobile operators in Iraq as citizens prefer face-to-face visits rather than remotely solve problems. Furthermore, lots of Iraqi citizens do not fully trust the new digital services supplied by operators particularly those that are directly related to financial issues, namely, money transfer, bill payments, paying taxes, declaration of permits, online reservations and the other monetary, such as online forms and applications. As a result, people would like better to solve them by directly contacting the concerned section or department. In addition, the outcomes of the interviews make known that the following are several factors influencing e-Government implementation, and usage in the government of Iraq, for instance usability and availability, culture issues, coordination and funding, security and privacy, accessibility, leadership, preparation users, lack of awareness, trust and privacy issues, IT skills (talents), legal issues and legislation, quality of service and information and the other factors such as, resistance to change and organizational issues. These challenges are similar to those challenges which are mentioned in the literature review and Iraqi egovernment challenges sections in this paper.

It cannot be seen that the project has achieved its goal since lots of problems still wait addressing. This study concludes that Iraqi e-Government project faces the challenges of political influence and infrastructure instability, corruption and poor resource management [2][3][15]. Until writing of this paper, Iraqi eGovernment suffers to progress! Even we sent several emails to the main portal of Iraq e-Government, but they did not reply us after months! Even it is now not working as it shown in figure 4.

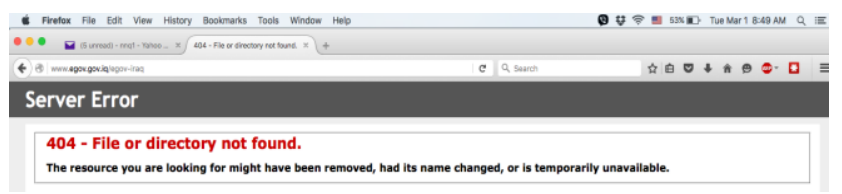

Figure 4: Online Iraqi government services

\section{CONCLUSION, LIMITATION AND FUTURE RESEARCH}

This study presented the outcome of a qualitative research into the issues surrounding the implementation and utilization of e-Government in the government of Iraq as articulate by the key e-Government official. Even though all its promise, e-Government in Iraq is still in its early stages and requires more and more research to improve the effectiveness of e-Services development and achieve wide public acceptance. The challenges of the eGovernment implementation could be technological such as, a country's infrastructure and economic issues can regularly disrupt e-Government services, and also cultural problems and a lack of funding for implementation are the other challenges for the eGovernment implementation [10]. All the mentioned 
challenges have been identified and discussed deeply in this study. Moreover, this paper gives substantial contributions to Iraqi's e-Government services initiative, in addition to the growing body of knowledge surrounding the topics of area. The study could further serve like a blueprint for the government of Iraq particular to overcome the barriers to the implementation of e-Government and to get better e-Government services based on sound research and confirmed principles.

In conclusion, this paper may help developing countries like Iraq to take advantages of e-Government services to transform the way they govern and facilitate the development of their economies. Furthermore, it can be said that the e-Government services implementation and design have its challenges and obstacles. However, various countries may have their own unique challenges [7]. As a final point, it is significant for policy makers to refrain from assuming that there are generic eGovernment challenges for all countries. Nevertheless, a careful review of the e-Government research and eGovernment project demonstrates that a big portion of the published research which was conducted in developed nations. The outcome of this study reveals that public awareness, infrastructural constraints, trust, access cost and the lack of an enabling lawful framework stay the primary challenges facing the implementation of the eGovernment in Iraq.

In the light of the knowledge obtained from this study and the primary finding presented in this research, the researchers of this study provide the following recommendations:

- Alteration to e-Government services ought to be treated like a reformation process, not only the computerization of government actions and operations

- Understand the fundamental reasons for pursuing e-Government services, before committing the resource and time. What's more, the main necessary to success the implementing eGovernment services proposal is political support

- Overcome and manager resistance to change. The main goals of transformation should be explained to employees. Be obvious that employees are not the opponent or the aims of reform. Also, new jobs will be explained clearly for all the employees

- Using ideas from the other countries that have successfully implemented the e-Government project and strategy

As future task, the researchers of this study next step involve conducting a huge scale survey that will explore e-Government adoption from the end users perspective. In addition, the researchers have a good plan to investigate and conduct more researches on eGovernment strategy, e-Government initiative and eGovernment willingness within the Iraqian context.

\section{REFERENCES}

[1] M. A. Alshehri and S. Drew, "Implementation of e-Government: Advantages and Challenges," Int. Conf. E-Activity Lead. Technol. 2010, pp. 79-86, 2010.

[2] P. Work, A. Ask, and M. Al-dabbagh, "Electronic Government in Iraq : Challenges of development and implementation," pp. 1-16, 2011.

[3] W. Jabbar, A. Ramasamy, and M. Othman, "CITIZEN IDENTIFICATION SYSTEM OF IRAQ : CHALLENGES AND BARRIERS IN ENABLING E - GOVERNMENT SERVICES," no. 125, pp. 399-404, 2013.

[4] A. A. Rabaai, "An Empirical Investigation on the Adoption of eGovernment in Developing Countries: The Case of Jordan," Comput. Inf. Sci., vol. 8, no. 3, 2015.

[5] S. R. I. Lanka, "EVALUATING THE ADOPTION OF EGOVERNMENT IN SRI LANKA: A CITIZENS 'PERSPECTIVE' MSc in Information Systems."

[6] P. Chatzoglou, "Factors affecting the intention to use eGovernment services : an extended approach," vol. 5, pp. 14891498, 2015.

[7] Heeks, R. (2003) Most E-Government-for-Development Projects Fail: How Can Risks Be Reduced. [Online] Available:

http://unpan1.un.org/intradoc/groups/public/documents/cafrad/unpan0 11226.pdf

[8] A. C. Approach and S. M. Shareef, "E-Government Initiatives in Kurdistan Region of Iraq :” pp. 1-3.

[9] A. Lect and H. Hasan, "E-Government in Iraq," vol. 14, no. 4, pp. 183-198, 2010

[10] Getrude Ntulo and J. Otike, "E - GOVERNMENT: ITS ROLE, IMPORTANCE AND CHALLENGES," vol. 53, no. September 2013, pp. 1-36, 2013.

[11]M. A. Mohammed, I. Huda, and M. N. Maslinda, "ELECTRONIC INFORMATION SHARING BETWEEN PUBLIC UNIVERSITIES AND MINISTRY OF HIGHER EDUCATION AND SCIENTIFIC RESEARCH: A PILOT STUDY," J. Theor. Appl. Inf. Technol., vol. 77, no. 2, pp. 151164, 2015.

[12] M. Georgescu, "Challenges for E-Government Strategy," vol. 3, no. 3, pp. 60-63, 2007.

[13]F. Zhao, K. N. Shen, and A. Collier, "Effects of national culture on e-government diffusion-A global study of 55 countries," Inf. Manag., vol. 51, no. 8, pp. 1005-1016, 2014.

[14]Patel, H. and Jacobson, D, "Factors Influencing Citizen Adoption of E-Government:" A Review and Critical Assessment. Proceedings of the $16^{\text {th }}$ European Conference on Information Systems, Galway, 9-11 June 2008, 176-188.

[15] O. O. Richard, "E-GOVERNMENT IN DEVELOPING COUNTRIES : THE CASE OF NIGERIA Olusoyi Olatokunbo Richard, Ashaye," no. April, 2014.

[16] United Nations. (2016) UN e-Government Survey on Iraq. [Online]. Available:

https://publicadministration.un.org/egovkb/en-us/Data/CountryInformation/id/80-Iraq/dataYear/2014

[17] S. Al-Shafi, and V. Weerakkody. "Factors affecting egovernment adoption in the state of Qatar". 2010

[18] S. AlAwadhi, and A. Morris. "Factors influencing the adoption of e-government services". Journal of Software. vol. 4, no. 6, pp. 584-590, 2009

[19] Al-hawari, A., Mohammad Ahmad, and M. Samar. "The influence of technology acceptance model (tam) factors on students' e-satisfaction and e-retention within the context of uae e-learning". Education, Business and Society: Contemporary Middle Eastern Issues. vol. 3, no. 4, pp. 299-314, 2010. 